\title{
Impedance functions of end-bearing inclined piles *
}

\author{
L.A. Padrón ${ }^{1}$, J.J. Aznárez ${ }^{1}$, O.Maeso $^{1}$, M.Saitoh $^{2}$ \\ ${ }^{1}$ Instituto Universitario de Sistemas Inteligentes y Aplicaciones Numéricas en Ingeniería \\ (SIANI) Universidad de Las Palmas de Gran Canaria \\ Edificio Central del Parque Científico y Tecnológico \\ Campus Universitario de Tafira, 35017, Las Palmas de Gran Canaria, Spain \\ ${ }^{2}$ Graduate School of Science and Engineering, Saitama University \\ 255 Shimo-Okubo, Sakura-Ku, Saitama, Japan
}

20 January 2012

\begin{abstract}
In this work, stiffness and damping functions of pile foundations with inclined end-bearing piles have been computed for square $2 \times 2$ and $3 \times 3$ pile groups embedded in a soft stratum overlaying a rigid bedrock. Results are presented in a set of dimensionless plots for two values of pile-soil stiffness ratio, three rake angles $\left(10^{\circ}, 20^{\circ}\right.$ and $30^{\circ}$, together with the vertical case) and three different directions of inclination of the piles with respect to the excitation. The paper also investigates the influence that the assumption of a perfectly rigid bedrock and fixed boundary conditions at the pile tips have on the impedance functions. Stiffness and damping coefficients of batter pile groups embedded in a half-space are also displayed for reference, and the more important features of the presented curves are discussed. The fundamental frequencies of the soil layer are clearly reflected in the impedance functions, but additional resonances, related to phenomena involving both soil layer resonance and pile-to-pile interaction, are also observed in the horizontal mode for higher frequencies.
\end{abstract}

\section{Introduction}

Only a small fraction of the studies related to the seismic response of pile foundations and pile supported structures deal with configurations that include inclined elements. However, batter piles are increasingly being used again to withstand large static and dynamic lateral loads, once they have regained the trust of engineers after the different incidents that occurred during the 1990s [1,2]. This fact, together with the potential advantages that could be derived from the proper use of batter piles, is fostering new efforts to obtain a better understanding of the seismic response of raked pile foundations. As a consequence, some interesting studies addressing the seismic response of inclined piles from different perspectives have been recently published $[2,3,4,5,6,7,8,9,10,11]$.

One of the aspects of the problem where further research is needed is the estimation of impedance functions that can be later used to perform seismic analyses through substructuring techniques. Therefore, and taking into account that, in many occasions, pile foundations are installed in soft soil layers overlaying a much stiffer soil or rock, this work focuses on the computation and analysis of stiffness and damping functions of end-bearing batter pile foundations embedded in a soft stratum overlying a hard bedrock.

${ }^{*}$ This is the peer reviewed version of the following article: L.A. Padrón, J.J. Aznárez, O.Maeso, M.Saitoh, Impedance functions of end-bearing inclined piles, Soil Dynamics and Earthquake Engineering 38 (2012) 97-108, which has been published in final form at http://dx.doi.org/10.1016/j.soildyn.2012.01.010. This work is released with a Creative Commons Attribution Non-Commercial No Derivatives License. 

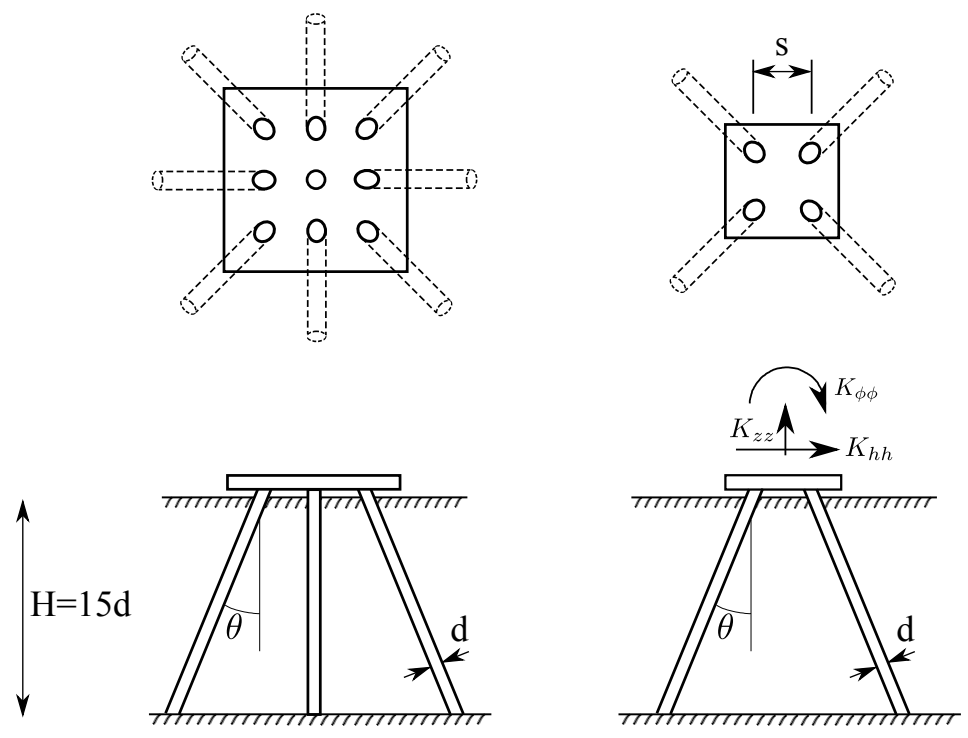

Figure 1: Problem definition

Regarding the organization of the rest of this article, next section defines the problem at hand and presents the methodology and numerical tools that have been used to compute the impedance functions. Then, the influence that bedrock stiffness and pile tip boundary conditions have on impedance functions is assessed. Afterwards, stiffness and damping coefficients corresponding to $2 \times 2$ and $3 \times 3$ pile groups with two different pile-soil stiffness ratios and three different directions of inclination of the piles with respect to the excitation are presented in a set of dimensionless plots. Here, three angles of inclination, together with the vertical case, are analyzed for all relevant modes. Also, and in order to estimate the magnitude of the influence of the presence of the bedrock, results are compared to those corresponding to the homogeneous half-space.

\section{Problem definition and methodology}

The system under analysis is a model of an end-bearing pile foundation composed by 4 or 9 inclined piles, arranged in regular square groups, and embedded in a soft homogeneous stratum overlaying a perfectly rigid bedrock. The main geometrical parameters of the system are depicted in Figure 1, where a $2 \times 2$ and a $3 \times 3$ pile groups are presented together with the symbols used to denote pile diameter $(d)$, stratum depth $(H=15 d)$, angle of inclination of the piles $(\theta)$ and pile-to-pile separation $(s)$. Pile heads will be assumed to be constrained (through fixed-head connection conditions) to a rigid massless pile cap which is able to rotate and which is not in contact with the ground surface. In general, pile tips will be considered to be fixed to a rigid bedrock, so that no displacements or rotations are allowed, although some results will be presented in which this conditions are relaxed.

In this work, the problem is solved using a 3-D coupled boundary element - finite element formulation previously presented and used to study some problems related to the dynamic response of both vertical and inclined piles $[8,12,13,14,15]$. Reference [8], in particular, presented impedance functions of inclined piles in a half-space as a previous step for the dynamic analysis of end-bearing raked pile foundations carried out in this work. Some of those previous results are used here, only for comparison or as a limiting case, to help gaining some insight into the most important aspects governing the system response.

The soil layer is modeled using the boundary element method as an unbounded homogeneous isotropic viscoelastic medium with hysteretic damping through complex-valued material properties of the type $E=\operatorname{Re}(E)(1+2 i \beta)$, being $\beta$ the hysteretic damping ratio. Radiation damping 


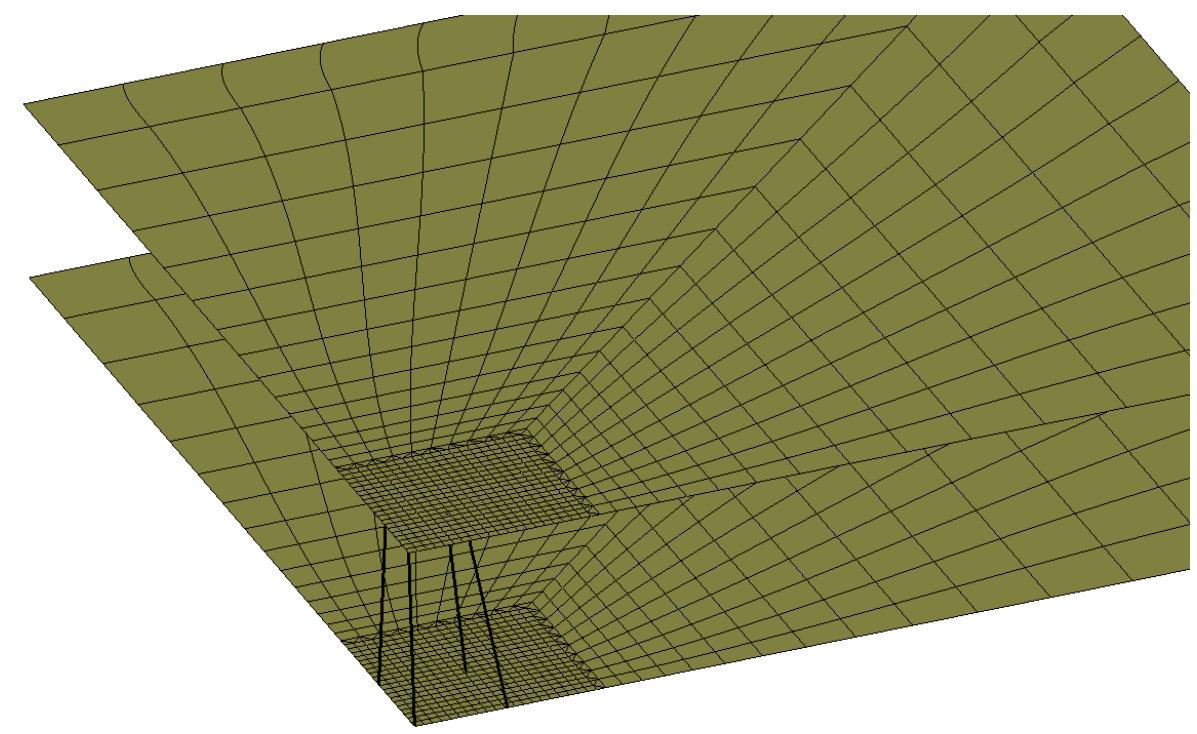

Figure 2: Boundary element - finite element mesh for a $3 \times 3$ pile group

is rigorously taken into account, as it is inherent to the boundary integral formulation used to model the soil regions. On the other hand, piles are modeled as Euler-Bernoulli beams with axial deformation using finite elements, and fully bonded contact conditions are established between piles and soils. The main reasons of using this formulation for this problem are: a) it retains all advantages of boundary element methods for soil-structure interaction problems, while $b$ ) thanks to the use of beam finite elements for the piles, meshing efforts and mesh complexity decrease dramatically together with the number of degrees of freedom and the associated computational effort, which allows to carry out parametric analyses as the one presented in this paper. The developed code takes advantage of the symmetry properties of the problem and needs only the mesh corresponding to a quarter of the geometry, as can be seen in figure 2, where a mesh used to obtain results presented in this work for a $3 \times 3$ pile group with inclined elements is shown. For more details on the formulation and the implementation, the interested reader is referred to references $[8,15]$.

The impedance functions are defined as the ratio between the steady-state force (or moment) applied at the pile cap and the resulting displacement (or rotation). These complex-valued functions will be presented in the form $K=k+i d$, being $i=\sqrt{-1}, k$ the stiffness function and $d$ the damping function. Note that this form has been chosen in opposition to the probably more traditional $K=k+i a_{o} c$ in order to be able to visualize more clearly the lack of radiation damping at low frequencies due to the presence of a bedrock, i.e, the cut-off frequencies. Horizontal $K_{h h}$, rocking $K_{\phi \phi}$, crossed horizontal-rocking $K_{\phi h}$ and vertical $K_{z z}$ impedance functions will be presented in dimensionless plots normalized by $E_{s} d, E_{s} d^{3}, E_{s} d^{2}$ and $E_{s} d$ respectively, where $E_{s}$ is the Young's modulus of the soil. These stiffness and damping coefficients are presented as functions of the dimensionless frequency $a_{o}=\omega d / c_{s}$, ranging from 0 to 1 , and being $\omega$ the circular frequency of the excitation and $c_{s}$ the velocity of the shear waves in the soil layer. In general, pile foundations are embedded in soil layers where shear wave velocity ranges from $c_{s}=50 \mathrm{~m} / \mathrm{s}$ (very soft) to $c_{s}=300 \mathrm{~m} / \mathrm{s}$ (hard). If the diameter of a representative pile is assumed to be $d=1 \mathrm{~m}$, the results presented in this paper covered up to $8 \mathrm{~Hz}$ for $c_{s}=50 \mathrm{~m} / \mathrm{s}$, or up to $50 \mathrm{~Hz}$ if $c_{s}=300 \mathrm{~m} / \mathrm{s}$, resulting in a comprehensive excitation frequency range for the problem of pile foundations subjected to earthquake waves.

The following values are used for the different properties defining the system: pile-soil modulus ratios $E_{p} / E_{s}=10^{2}$ and $10^{3}$; soil-pile density ratio $\rho_{s} / \rho_{p}=0.7$; soil internal damping coefficient $\beta_{s}=0.05$; pile internal damping coefficient $\beta_{p}=0.0$; soil Poisson's ratio $\nu_{s}=0.4$; pile Poisson's ratio $\nu_{p}=0.25$; pile-to-pile separation ratio $s / d=5$; stratum depth $H=15 d$; and pile rake angles $\theta=0^{\circ}$ (vertical piles), $10^{\circ}, 20^{\circ}$ and $30^{\circ}$. As shown in the sketches that illustrate 


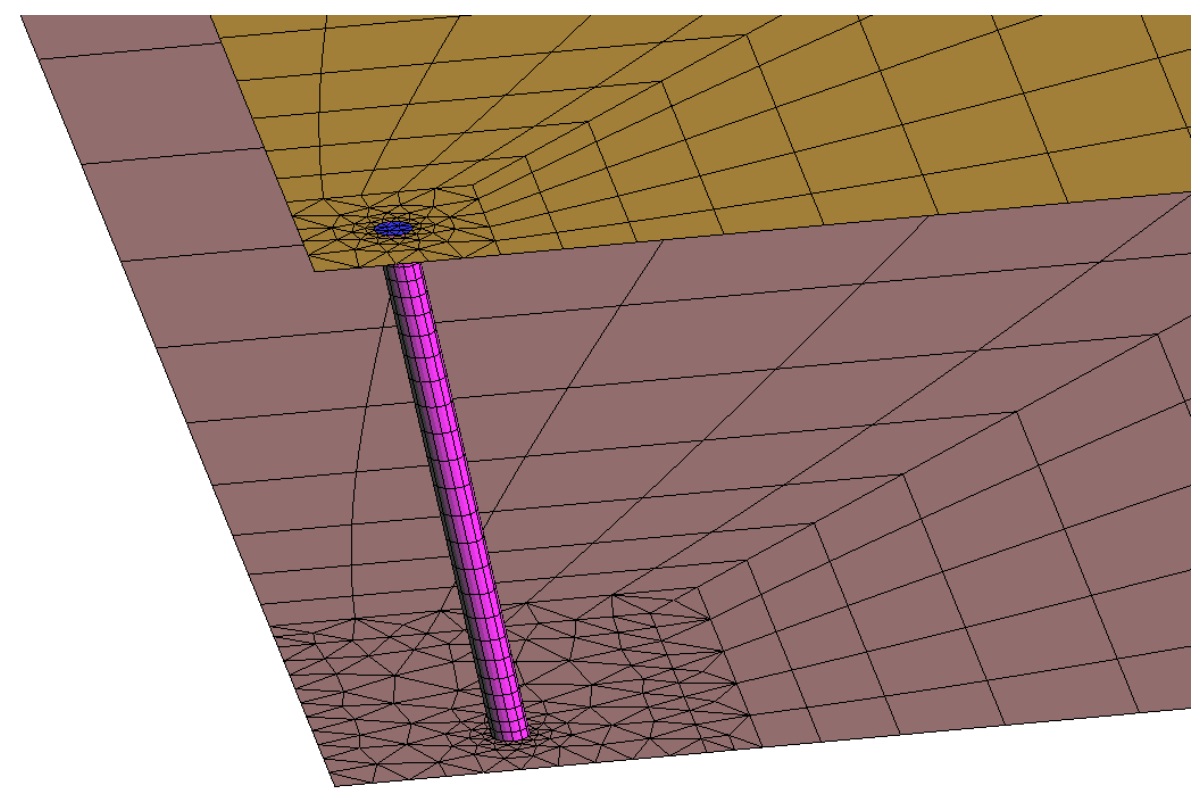

Figure 3: Multidomain boundary element mesh used to model the $2 \times 2$ pile groups with $10^{\circ}$ inclined elements and $s / d=5$

each plot, different planes of inclination are analyzed for each vibrating mode.

\subsection{Comparison results between BEM-BEM and BEM-FEM formulations}

All results presented in section 5 have been obtained using the coupled BEM-FEM formulation described above. In order to qualify the code for this problem, it has been contrasted with a more rigorous multidomain boundary element code [16]. The boundary element mesh used in this chapter is shown in Figure 3. This mesh is formed by 3244 nodes arranged in 960 quadratic elements, being the free surface total width 8 times greater than the stratum depth. On the other hand, the BEM-FEM mesh is formed by 2210 boundary element nodes, arranged in 564 boundary elements, and also by around 30 finite element nodes arranged in 10 elements.

Figures 4 to 7 present the comparisons between the coupled BEM-FEM and the multidomain BEM formulations for horizontal, rocking, crossed and vertical impedance functions for a $2 \times 2$ pile group with a separation ratio $s / d=5$ and $10^{\circ}$ rake angle. Results for two pile-soil stiffness ratios and two alignments of the inclined piles in relation to the direction of the excitation are presented.

It can be seen that, in all cases, the agreement is very good. The largest differences occur for the rocking impedance and $E_{p} / E_{s}=10^{3}$, reaching values of $7.5 \%$. However, the differences are always much smaller than $3 \%$ in the rest of cases. These differences can be explained in part by the fact that the meshes used for both methods are not identical. Consequently, the acceptable magnitude of the differences, and the great reduction of computation time (around $75 \%$ reduction in these problems) and meshing efforts related to the simplified BEM-FEM formulation, allows the use of this coupled method to perform the parametric analyses presented in sections 4 and 5 .

\section{Influence of perfectly rigid bedrock hypothesis}

As mentioned in section 1, piles embedded in a soft stratum and resting on a rigid bedrock will be considered in this work. In order to evaluate the influence of the perfectly rigid bedrock hypothesis in comparison to a flexible bedrock, figure 8 presents horizontal and vertical impedance functions of a $2 \times 2$ pile group with $10^{\circ}$ raked piles embedded in a soft stratum and resting 
on hard but flexible bedrock. Such bedrock is defined by a Young's modulus ten times greater than that of the soft stratum, but identical density and histeretic damping ratio. Therefore, the velocity of the shear waves in such flexible bedrock is $\sqrt{10} \simeq 3.16$ times greater than that on the soft stratum. As a limiting case of the flexible bedrock, results corresponding to a half-space, obtained from a previous work [8] and entailing only about a $20 \%$ of computational effort, are also presented for comparison. Both $E_{p} / E_{s}=10^{2}$ and $10^{3}$ are considered. The results have been obtained using the multidomain boundary element formulation and the boundary element mesh shown in figure 3 .

As expected, the presence of a non-perfectly rigid bedrock reduces slightly the magnitude of the oscillations associated to the soft stratum natural frequencies, producing therefore slightly smoother curves. This effect becomes apparent in the horizontal impedance functions, but is not so important for the vertical modes where, as the axial stiffness of the piles is much higher, the influence of the natural frequencies of the stratum is much smaller. It is also very important the decrease in some static stiffnesses, mainly the vertical one by 71 and $16 \%$ for $E_{p} / E_{s}=10^{3}$ and $10^{2}$ respectively (note the $\times 2$ at the bottom left plot, indicating that the corresponding dimensionless vertical stiffness for a perfectly rigid bedrock and soft soil is twice as shown, i.e., around 220). This decrease in the static stiffness is also noticeable when the pile cap vibrates horizontally parallelly to the plane of inclination of the piles (top plot of figure 8), in which case the horizontal static stiffness decreases by $27 \%$ for the soft soil $\left(E_{p} / E_{s}=10^{3}\right)$. Looking at the whole frequency range, differences for the horizontal impedance functions due to a perfectly or non-perfectly rigid bedrock are small for the stiff soil $\left(E_{p} / E_{s}=10^{2}\right)$, reaching values of $9 \%$ only in some peaks, but significant for soft soils $\left(E_{p} / E_{s}=10^{3}\right)$, with values up to $35 \%$. In the vertical case, differences are much higher for frequencies $a_{o}<0.4$, with differences up to $25 \%$ for stiff soils and up to $80 \%$ for soft soils. On the other hand, differences in damping functions are smaller than those appreciated in the stiffness functions, with the exception of the vertical mode, especially for soft soils, where differences reach values of $100 \%$. Cut-off frequencies are clearly marked also with a flexible bedrock, though slightly smoother.

As anticipated, differences increase for softer soils as the load transferred to the bedrock increases. Obviously, the degree at which the real solution at a particular case moves away from that corresponding to a perfectly rigid bedrock and approaches that of a half-space will depend on the stiffness contrast between soil and bedrock found on site, and could be an issue of further research. However, for most cases shown here, the hypothesis of a perfectly rigid bedrock is quite sound for the horizontal case, but might be only approximate for the vertical and rocking ones.

\section{Influence of boundary condition at the pile tip}

Another issue when modeling a real pile foundation is the boundary condition at the tip of a pile driven into (or resting on) a bedrock, as such boundary condition will never correspond exactly to a perfectly hinged end nor to a perfectly fixed end neither. For this reason, it is interesting to perform a preliminary evaluation of the influence of this pile tip boundary condition on the impedance functions of end-bearing raked pile groups.

To this end, figures 9 and 10 present comparisons for the horizontal and vertical impedance functions obtained considering fixed or hinged boundary conditions at the pile tips. Again, results for two pile-soil stiffness ratios and two alignments of the inclined piles in relation to the direction of the excitation are presented.

It can be seen that the influence of the boundary condition at the pile tip is extremely small, being practically zero for the vertical impedance and, in all cases, for stiff soils $\left(E_{p} / E_{s}=10^{2}\right)$. As for the rest of cases, there can be found certain points where differences reach $15 \%$, but in general they are of the order of $1 \%$. Rocking and crossed impedance functions are not shown but are also virtually coincident for both pile tip boundary conditions. Therefore, it can be said that the boundary condition at the pile tip is of secondary importance to the dynamic response of 
the foundation, at least in the range of pile slenderness and pile-soil stiffness ratios considered in this study. For this reason, and taking into account that a fixed tip condition is generally closer to the real situations, all results presented in section 5 are obtained considering fixed boundary conditions at pile tips.

\section{Impedance functions for batter pile foundations}

In this section, horizontal, rocking, crossed horizontal-rocking and vertical impedance functions of pile foundations with inclined elements are presented. Figures 11 to 14 present results for $2 \times 2$ pile groups, while figures 15 to 18 correspond to $3 \times 3$ pile groups. Each figure, corresponding to a certain mode, presents stiffness and damping functions for all the considered rake angles $\left(0^{\circ}\right.$, $10^{\circ}, 20^{\circ}$ and $30^{\circ}$ ) and pile-soil stiffness ratios $E_{p} / E_{s}=10^{3}$ (top) and $E_{p} / E_{s}=10^{2}$ (bottom). Also, each column corresponds to a certain configuration of the foundation, i.e., with the piles either inclined in the same direction of the excitation, perpendicular to it, or rotated $45^{\circ}$. In each column, a sketch represents the specific pile configuration and its relation with the excitation. All results are adimensionalized using the soil Young's modulus $E_{s}$ and the pile diameter $d$. Also, in order to allow easy comparison between impedances of the different configurations, all subplots in a row have always the same scale. It is also interesting to compare impedances for the problem at hand with those for the same foundations but embedded on a homogeneous half-space with the properties of the soft stratum of the former problem. For this reason, such functions (from [8]) are also plotted for reference in figures 11 through 18.

As anticipated, the soil profile has a very important influence on the foundation impedance functions. The soil layer fundamental frequencies associated to shear and dilatational waves are $a_{o}=0.105$ and $a_{o}=0.257$ respectively. This two frequencies are clearly marked in the horizontal impedance functions with the associated reduction in the stiffness function, but they do not become apparent in the rocking and vertical cases due to the relative high axial stiffness of the end-bearing piles. These fundamental frequencies also define cut-off frequencies below which radiation damping phenomena cannot develop and, consequently, the damping coefficients are extremely low. Such cut-off frequencies are slightly below the soil layer fundamental ones, and appear around $a_{o}=0.1$ for the horizontal modes, and around $a_{o}=0.2$ for the vertical and rocking modes.

The horizontal impedance functions (figures 11 and 15) show additional resonances above the two fundamental frequencies commented above. While such fundamental frequencies are marked exactly at the same point for all configurations, the position of the natural frequencies appearing for $a_{o}>0.3$ varies with rake angle, pile configuration and pile-soil stiffness contrast. These resonances are associated with two different phenomena that interact: a) pile-to-pile interaction, and $b$ ) soil layer resonances. In order to support this idea, figure 19 presents the horizontal impedance functions of a floating $2 \times 2$ pile group embedded in soil layers of different depths and with the piles inclined in a plane perpendicular to the direction of vibration. The rest of properties defining such foundation are: slenderness ratio $L / d=15$, rake angle $\theta=10^{\circ}$, soil stiffness contrast ratios of $E_{p} / E_{s}=10^{3}$ and $10^{2}$, and three different depth ratios for the soil layers: $H / d=15,16.5$ and 18. The fundamental frequencies for the shear waves in these soil layers are $a_{o}=0.105, a_{o}=0.095$ and $a_{o}=0.087$, respectively. Figure 19 illustrates how, in this case, the resonances commented above appearing for $a_{o}>0.3$ correspond very closely to the second and third natural frequencies of the soil layer for the $\mathrm{S}$ waves, and how this correspondence is kept for all values of $H / d$ as the natural frequencies move to lower frequencies proportionally to the increase in the soil layer depth. This observation proofs that such resonances are indeed associated to the soil profile. However, this good correspondence between the impedance function resonances and the soil layer natural frequencies is not kept for all cases. For example, figures 11 and 15 show how the frequencies at which this resonances develop change with rake angle, soil stiffness and foundation configuration. Figure 20 shows how they change also for different pileto-pile separation ratios when the rest of parameters are kept constant (in this case also, the 
resonance frequencies associated to the soil layer fundamental frequencies do not change), which indeed indicates that pile-to-pile interaction, together with pile inclination and flexibility, plays also its role in this observed oscillations.

On the other hand, rocking impedance functions (figures 12 and 16) display, as expected, higher stiffness and smaller damping than when the inclined piles are embedded in a half-space, especially for the softer soil. However, the resonance associated with the pile group effects remains and develops nearly at the same frequencies. Similar observations can be made with regard to the vertical mode of vibration (figures 14 and 18).

Finally, figures 13 and 17 present the crossed horizontal-rocking impedance functions. A marked increase in the stiffness coefficients can be appreciated as the inclination of the pile augments (except for the case in the left for which the piles are inclined perpendicularly to the direction of the horizontal vibration). Such increase is substantially higher than that corresponding to the half-space case for $E_{p} / E_{s}=10^{3}$, although in such case damping keeps being negative in presence of a rigid bedrock. The increase in the stiffness coefficients entails a change of sign from negative to positive that implies that displacements and rotations at the pile cap become out of phase. This phenomenon will have a significant effect on the seismic response of the superstructure, which in general will display smaller displacements when founded on inclined rather than vertical piles $[2,9]$. Finally, it is worth noting that the oscillations observed in the horizontal impedance functions for $a_{o}>0.3$, not present neither in the rocking nor in the vertical cases, become apparent also in this case, especially for $E_{p} / E_{s}=10^{2}$.

\section{Conclusions and future research}

In this paper, impedance functions for $2 \times 2$ and $3 \times 3$ end-bearing pile groups with inclined elements are presented. These functions, computed using a coupled boundary element - finite element code, are presented in a set of dimensionless plots for certain representative configurations, and are expected to be useful also to practitioners. Horizontal, vertical, rocking and crossed horizontal-rocking stiffness and damping coefficients are presented as a function of dimensionless frequency. Before that, the influence of two common assumptions in the definition of the model have been assessed. It is shown, first, that the hypothesis of a perfectly rigid bedrock, in opposition of considering the actual bedrock stiffness, is perfectly sound for the horizontal vibration modes but might be only approximate for the vertical and rocking ones; and second, that considering a hinged or fixed pile tip is of secondary importance to the impedance functions of the foundation.

Different pile soil stiffness ratios, rake angles and planes of inclination have been considered. As expected, the results confirm the significant influence of rake angle, rigid bedrock and soil layer on the stiffness and damping coefficients, where the fundamental frequencies of both shear and dilatational modes of the soil layer are clearly reflected as marked minima in the horizontal and crossed stiffness functions, while the fundamental frequency associated to the shear waves in the soil layer defines the well known cut-off frequency for all modes below which damping is almost non-existent. Additional resonances, associated with the horizontal mode of vibration, and much deeper for the $3 \times 3$ configuration, are observed for higher frequencies. After analyzing some additional results, such oscillations have been related to phenomena involving both soil layer resonance and pile-to-pile interaction.

On the other hand, stiffness and damping functions of the same pile groups but embedded on a homogeneous half-space are also presented in most plots for reference and also in order to assess when could they be used as an approximation for the soil layer problem. Such curves, corresponding to a half-space with the properties of the soil layer of the original problem, also allows the identification of the influence of rigid bedrock and soil layer. It is shown that the stiffness functions for the homogeneous soil may work as a reference for stiff soil layers, but not for soft soil layers $\left(E_{p} / E_{s} \geq 10^{3}\right)$, for which huge differences (greater than $100 \%$ ) are observed. As for the damping coefficients, the horizontal mode of vibration produces similar 
amount of damping both for a homogeneous half-space and a soil layer on a rigid bedrock. On the contrary, all impedance functions associated with the vertical or rocking modes show significantly smaller damping for end-bearing pile foundations in a soil layer. Another noticeable effect of the presence of a rigid bedrock is the change of sign in the crossed horizontal-rocking stiffness and damping functions that arises for increasing rake angles for the softer soil and that reproduces what happens for stiffer soils even in case of a homogeneous half-space. This variation, quite significant, is expected to have a large impact on the seismic response of a superstructure, but the quantification of this effect needs further research.

Obviously, and in order to get a better understanding on whether batter piles play a beneficial or detrimental role in the seismic response of pile supported structures, more work needs to be done on this topic. Apart from the computation and validation of impedance functions of inclined pile foundations for other configurations, it would also be interesting to compute the corresponding kinematic interaction factors under different types of seismic waves and different angles of attack. This way, parametric substructuring analyses could be perform to study the influence of pile inclination on the seismic response of both foundation and superstructure, what could lead to the establishment of design recommendations for this type of systems.

\section{Acknowledgments}

This work was supported by the Ministerio de Ciencia e Innovación of Spain (Subdirección General de Proyectos de Investigación) through research project BIA2010-21399-C02-01 and co-financed by the European Fund of Regional Development (FEDER). It was also supported by the Agencia Canaria de Investigación, Innovación y Sociedad de la Información (ACIISI) of the Government of the Canary Islands, and by FEDER funds, through research project ProID20100224.

\section{References}

[1] Kavazanjian E. A driven-pile advantage: Batter piles. Piledriver 2006;Q4:21-25.

[2] Giannakou A, Gerolymos N, Gazetas G, Tazoh T, Anastasopoulos I. Seismic behavior of batter piles: elastic response. Journal of Geotechnical and Geoenvironmental Engineering 2010;136(9):1187-1199.

[3] Juran I, Benslimane A, Hanna S. Engineering analysis of dynamic behavior of micropile systems. Transportation Research Record 2001;1772:91-106.

[4] Sadek M, Shahrour I. Three-dimensional finite element analysis of the seismic behavior of inclined micropiles. Soil Dyn Earthquake Eng 2004;24:473-485.

[5] Poulos HG. Raked piles virtues and drawbacks. Journal of Geotechnical and Geoenvironmental Engineering 2006;132:795-803.

[6] Deng N, Kulesza R, Ostadan F. Seismic soil-pile group interaction analysis of a battered pile group. In Proc. 4th Int Conference on Earthquake Geotechnical Engineering (CD-ROM). Aristotle Univ. of Thessaloniki, Laboratory of Soil Mechanics, Foundation and Geotechnical Earthquake Engineering, Greece, 2007.

[7] Gerolymos N, Giannakou A, Anastasopoulos I, Gazetas G. Evidence of beneficial role of inclined piles: Observations and summary of numerical analyses. Bull Earthquake Eng 2008;6(4):705-722.

[8] Padrón LA, Aznárez JJ, Maeso O, Santana A. Dynamic stiffness of deep foundations with inclined piles. Earthquake Eng Struct Dyn 2010;39:1343-1367. 
[9] Kiyota S, Yonezawa T, Aoki H, Koda M, Nishioka H, Dewa T. Study on lateral resistance and application to railway structures of batter pile foundation. Japan Geotechnical Journal (In Japanese) 2010;5(2):293-307.

[10] Ghasemzadeh H, Alibeikloo M. Pile-soil-pile interaction in pile groups with batter piles under dynamic loads. Soil Dyn Earthquake Eng 2011;31(8):1159-1170.

[11] Isam S, Hassan A, Mhamed S. 3D elastoplastic analysis of the seismic performance of inclined mircropiles. Computers and Geotechnics 2012;39:1-7.

[12] Padrón LA, Aznárez JJ, Maeso O. BEM-FEM coupling model for the dynamic analysis of piles and pile groups. Eng Anal Bound Elem 2007;31:473-484.

[13] Padrón LA, Aznárez JJ, Maeso O. Dynamic analysis of piled foundations in stratified soils by a BEM-FEM model. Soil Dyn Earthquake Eng 2008;28:333-346.

[14] Padrón LA, Aznárez JJ, Maeso O. Dynamic structure-soil-structure interaction between nearby piled buildings under seismic excitation by BEM-FEM model. Soil Dyn Earthquake Eng 2009;29:1084-1096.

[15] Padrón LA, Aznárez JJ, Maeso O. 3-D boundary element - finite element method for the dynamic analysis of piled buildings. Eng Anal Bound Elem 2011;35:465-477.

[16] Maeso O, Aznárez JJ, García F. Dynamic impedances of piles and groups of piles in saturated soils. Comput Struct 2005;83:769-782. 

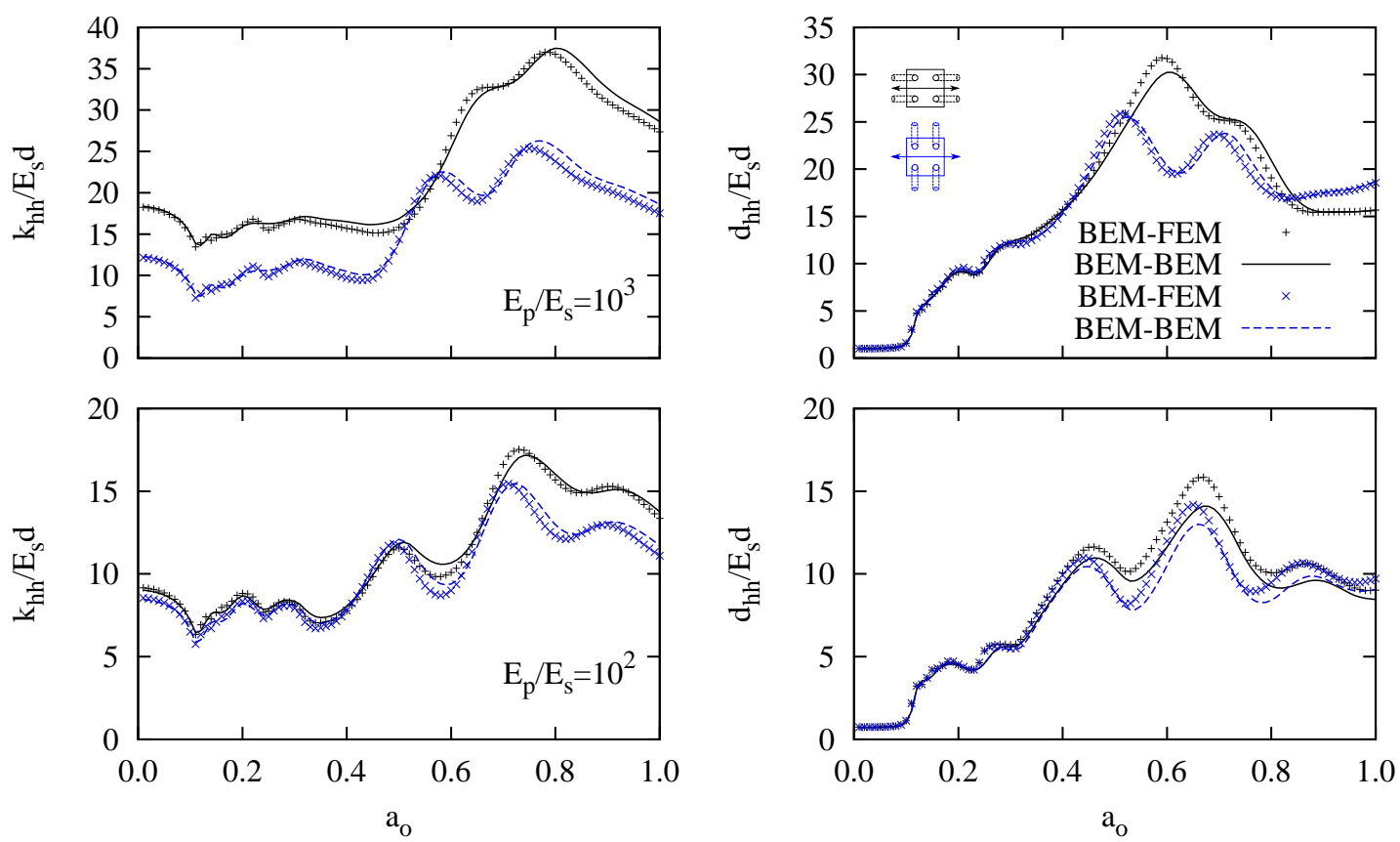

Figure 4: Comparison between BEM-BEM and BEM-FEM results. Horizontal impedance functions for a $2 \times 2$ pile groups with $10^{\circ}$ inclined elements and $s / d=5$.
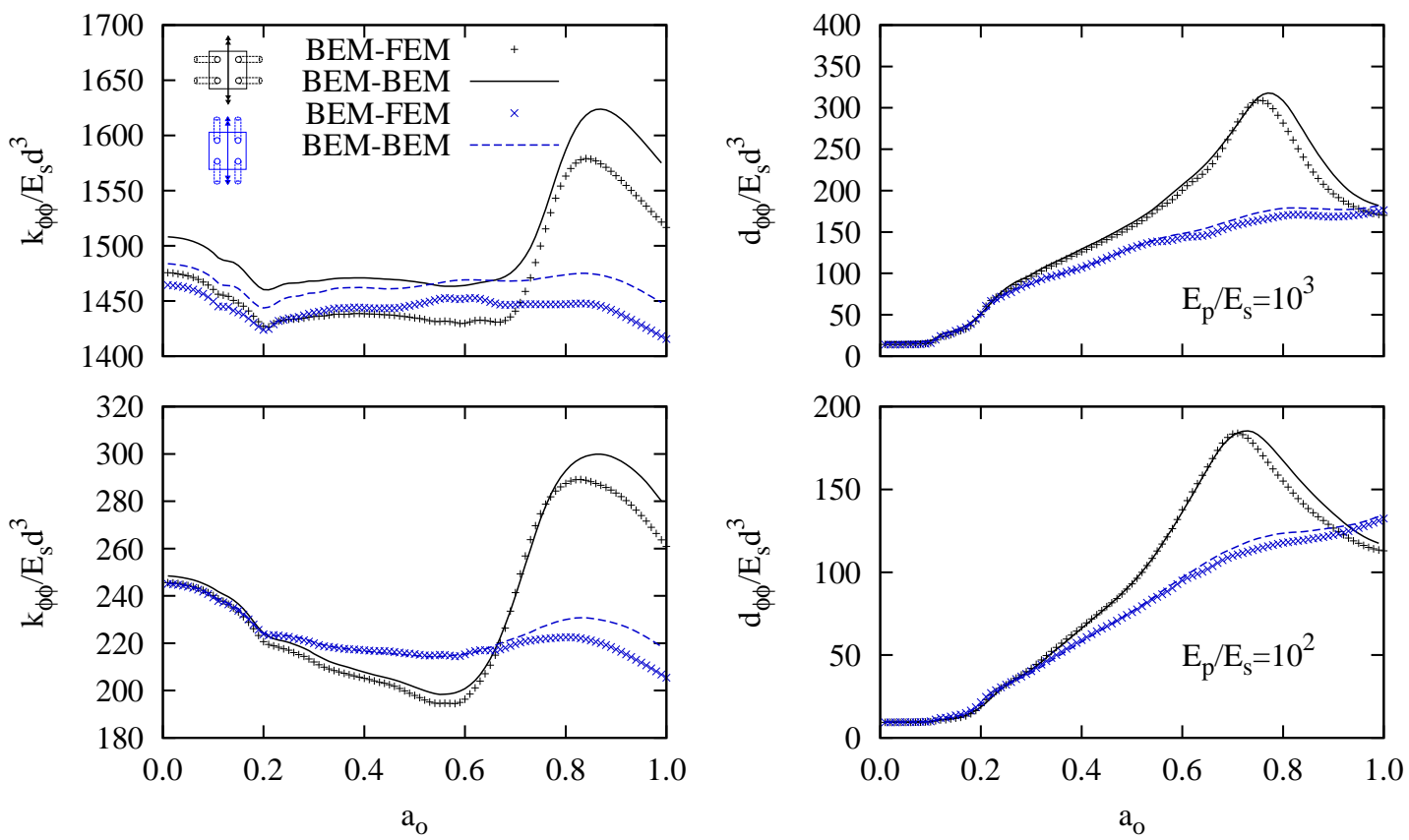

Figure 5: Comparison between BEM-BEM and BEM-FEM results. Rocking impedance functions for a $2 \times 2$ pile groups with $10^{\circ}$ inclined elements and $s / d=5$. 

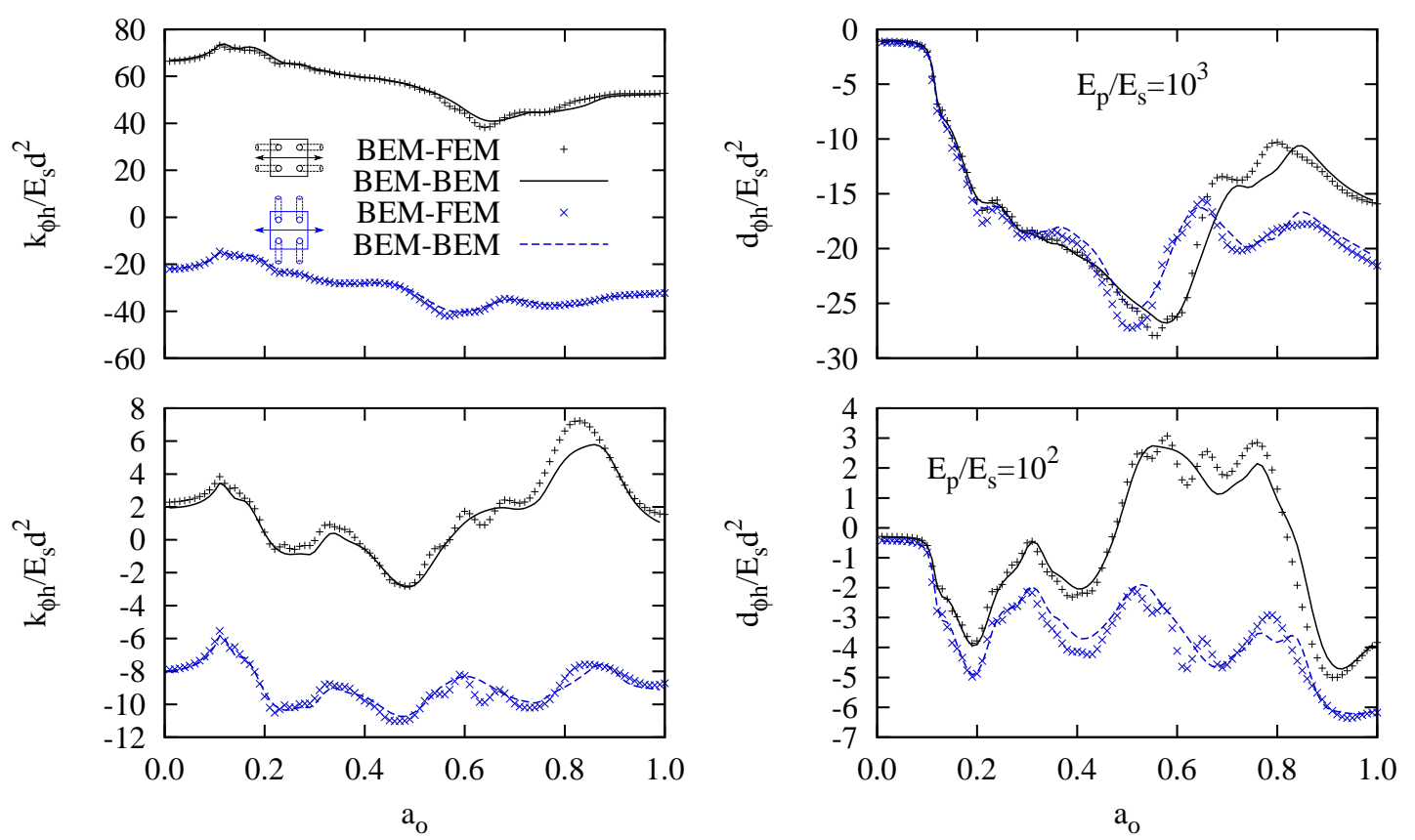

Figure 6: Comparison between BEM-BEM and BEM-FEM results. Crossed rocking-horizontal impedance functions of a $2 \times 2$ pile groups with $10^{\circ}$ inclined elements and $s / d=5$.
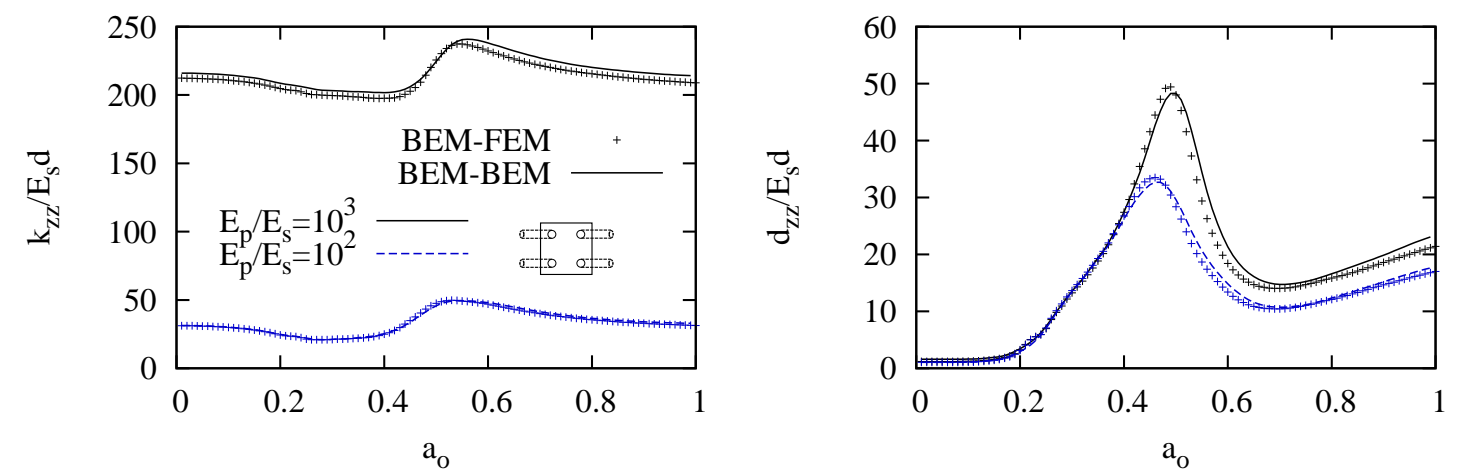

Figure 7: Comparison between BEM-BEM and BEM-FEM results. Vertical impedance functions for a $2 \times 2$ pile groups with $10^{\circ}$ inclined elements and $s / d=5$. 

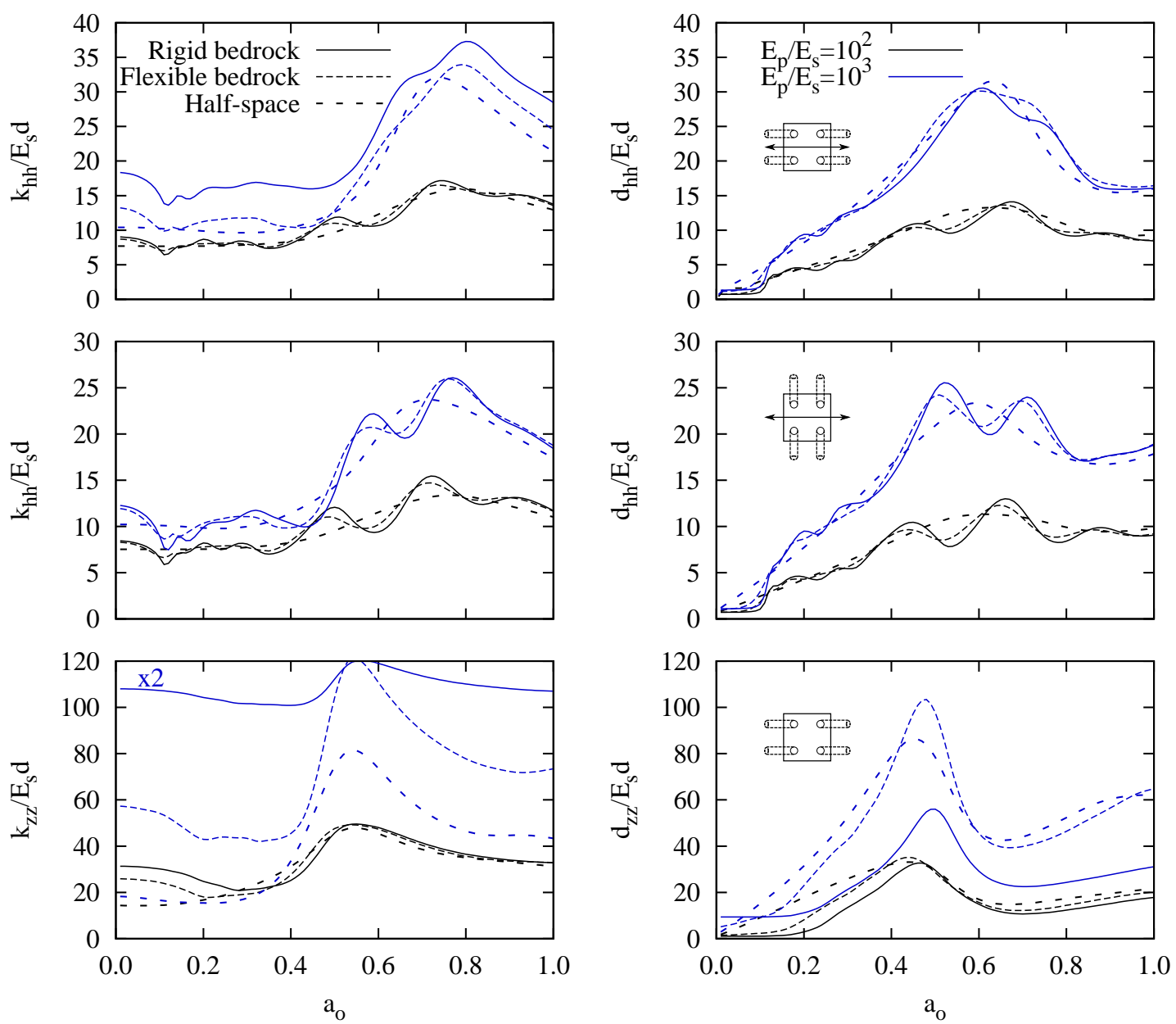

Figure 8: Comparison between impedance functions for perfectly rigid or flexible bedrock. $2 \times 2$ pile groups with $10^{\circ}$ inclined elements and $s / d=5 . E_{p} / E_{s}=10^{2} . E_{s} / E_{b}=10$
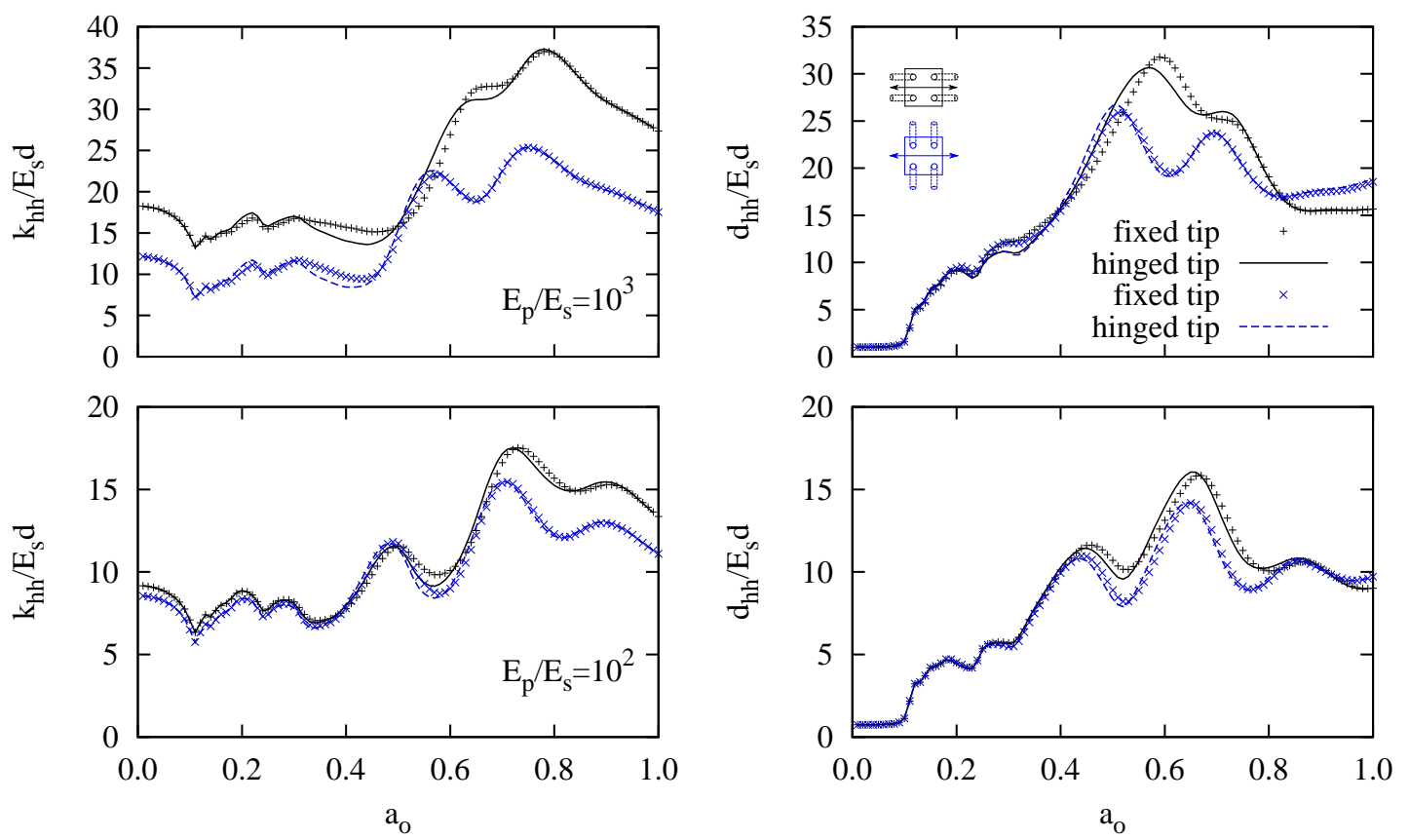

Figure 9: Horizontal impedance functions for a $2 \times 2$ pile groups with $10^{\circ}$ inclined elements and $s / d=5$. Comparison between fixed and hinged tip boundary conditions. 

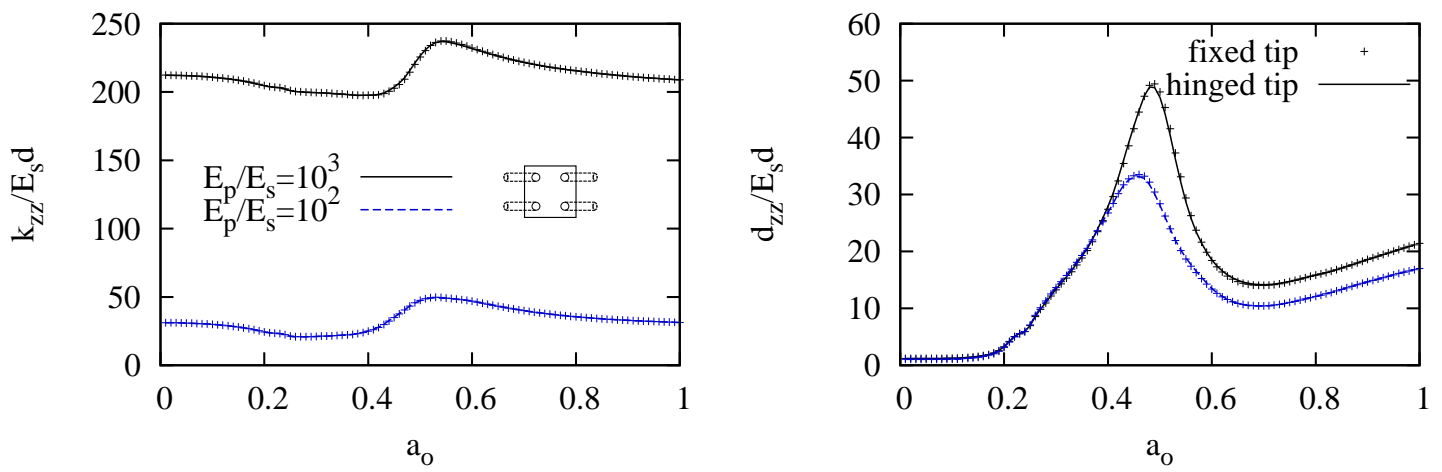

Figure 10: Vertical impedance functions for a $2 \times 2$ pile groups with $10^{\circ}$ inclined elements and $s / d=5$. Comparison between fixed and hinged tip boundary conditions.
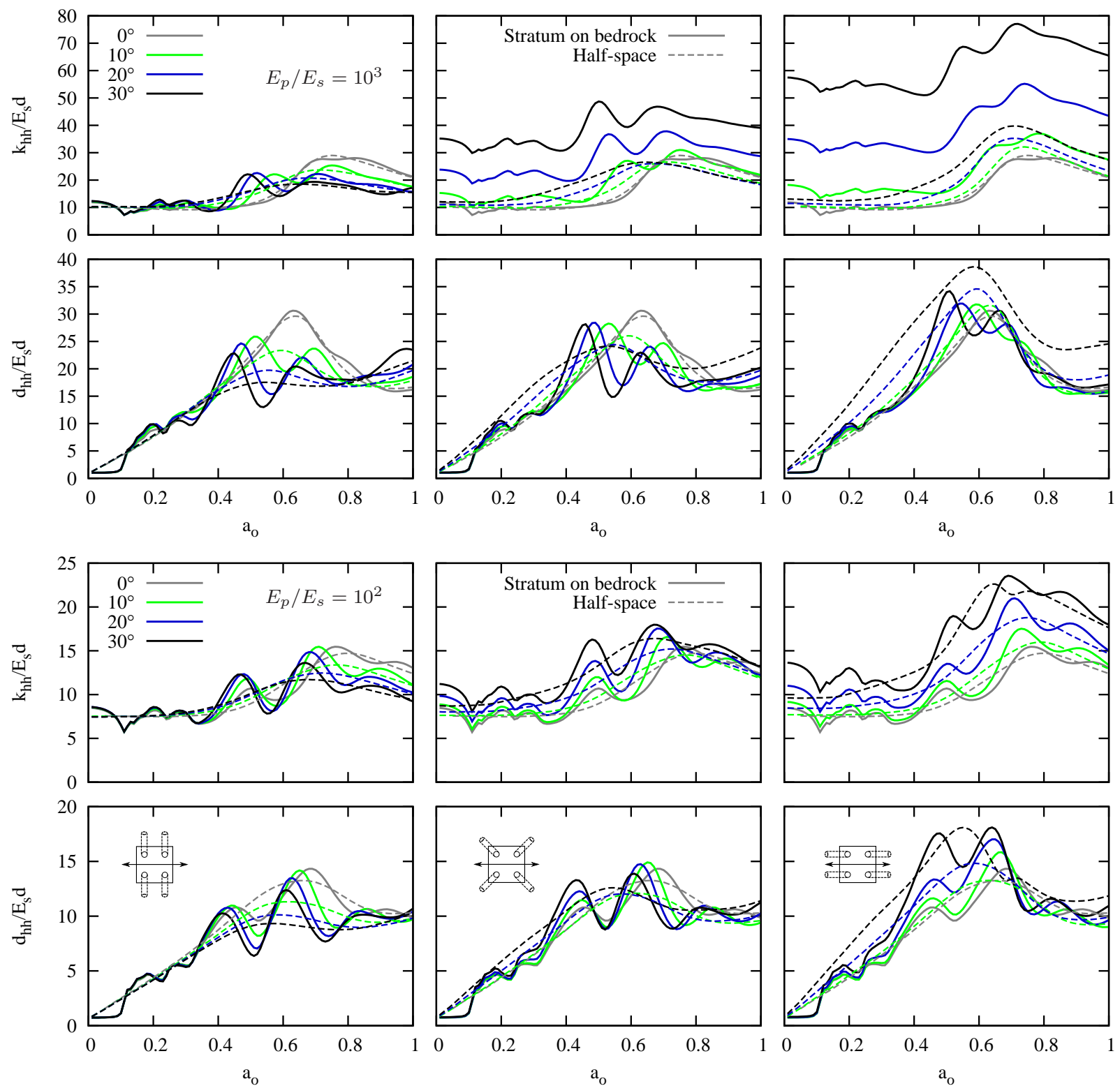

Figure 11: Horizontal impedance functions for $2 \times 2$ pile groups with inclined elements. $s / d=5$. $E_{p} / E_{s}=10^{3}$ (top) and $E_{p} / E_{s}=10^{2}$ (bottom). 

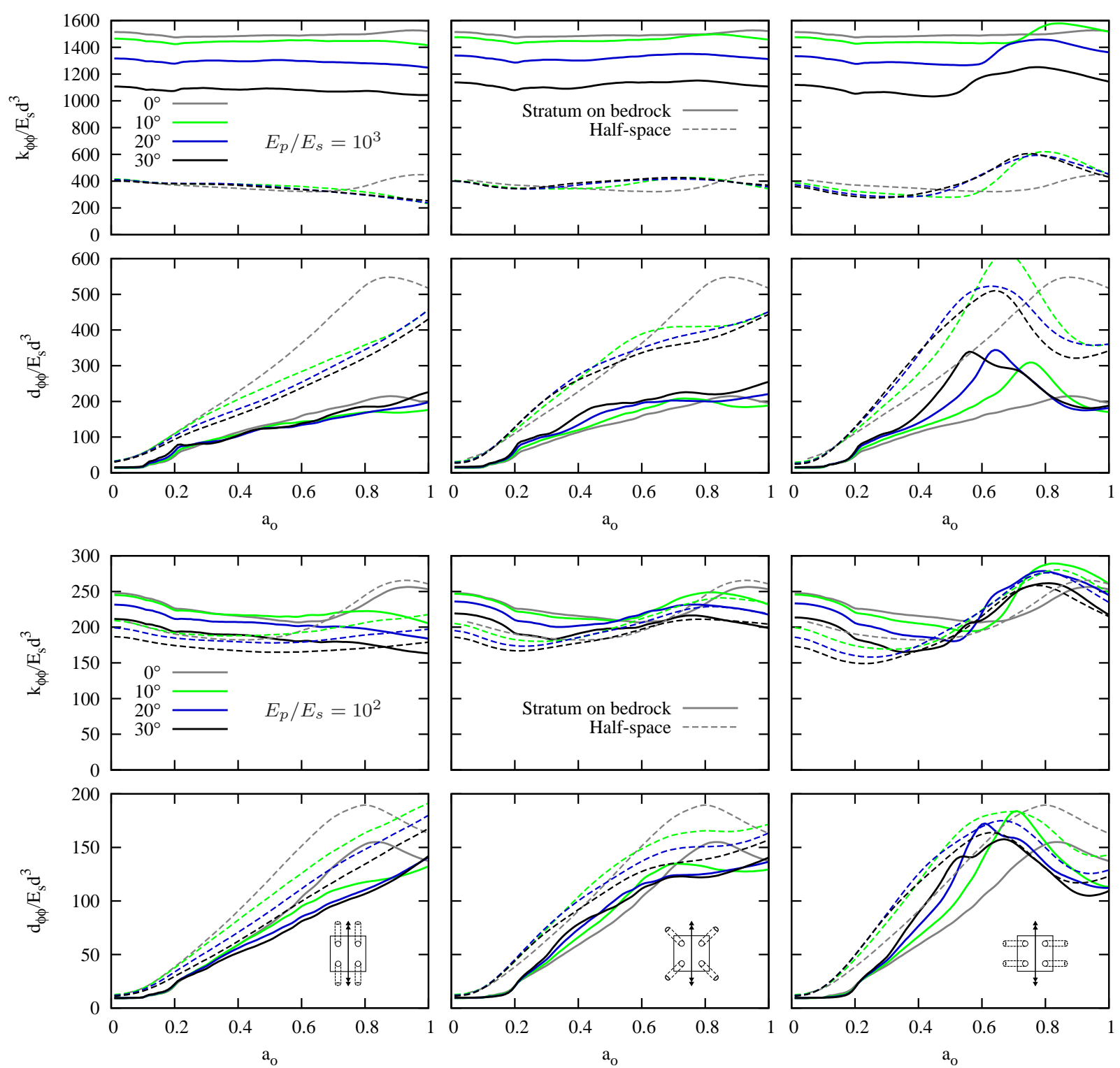

Figure 12: Rocking impedance functions for $2 \times 2$ pile groups with inclined elements. $s / d=5$. $E_{p} / E_{s}=10^{3}$ (top) and $E_{p} / E_{s}=10^{2}$ (bottom). 

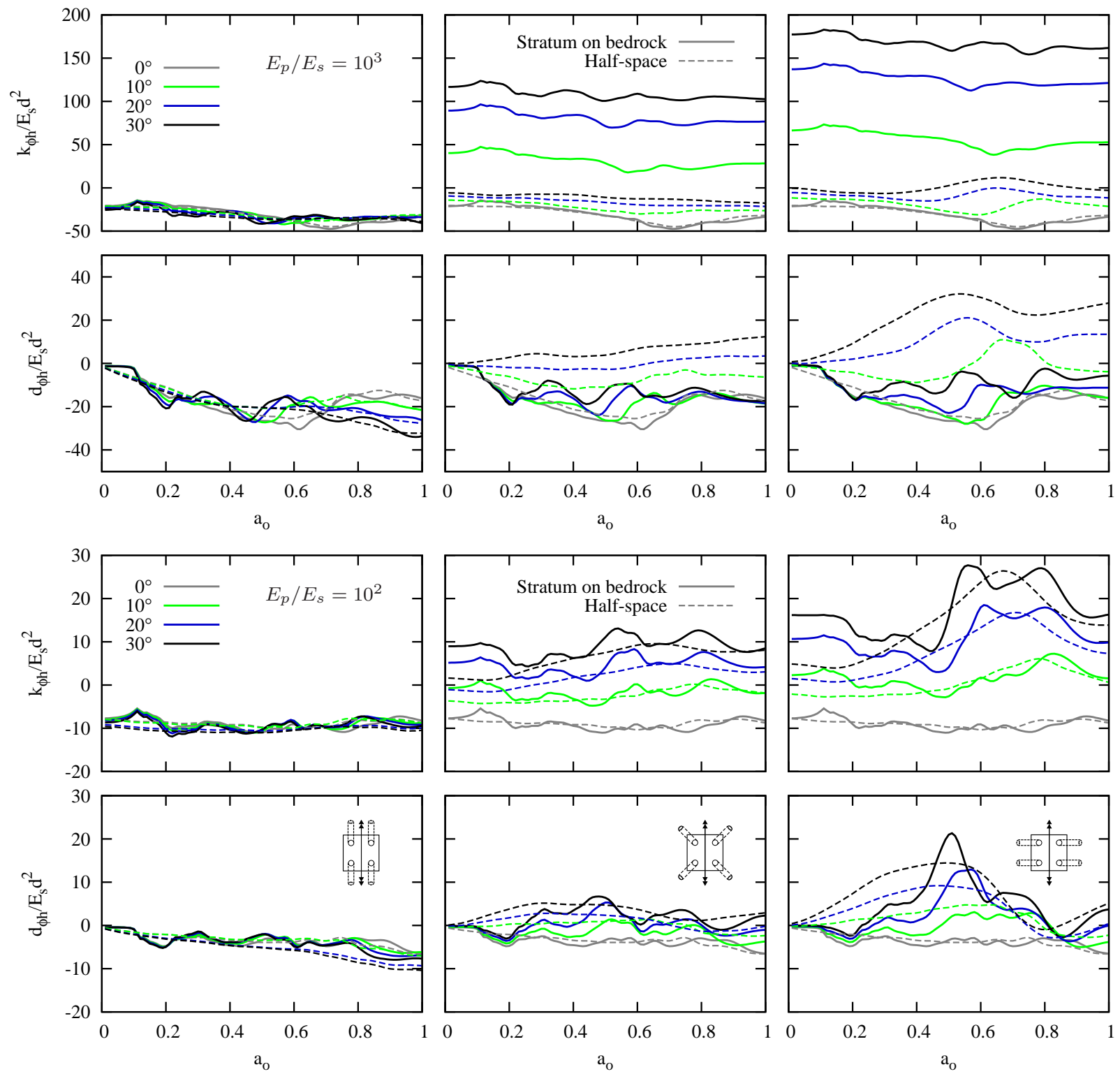

Figure 13: Crossed horizontal-rocking impedance functions for $2 \times 2$ pile groups with inclined elements. $s / d=5 . E_{p} / E_{s}=10^{3}$ (top) and $E_{p} / E_{s}=10^{2}$ (bottom). 

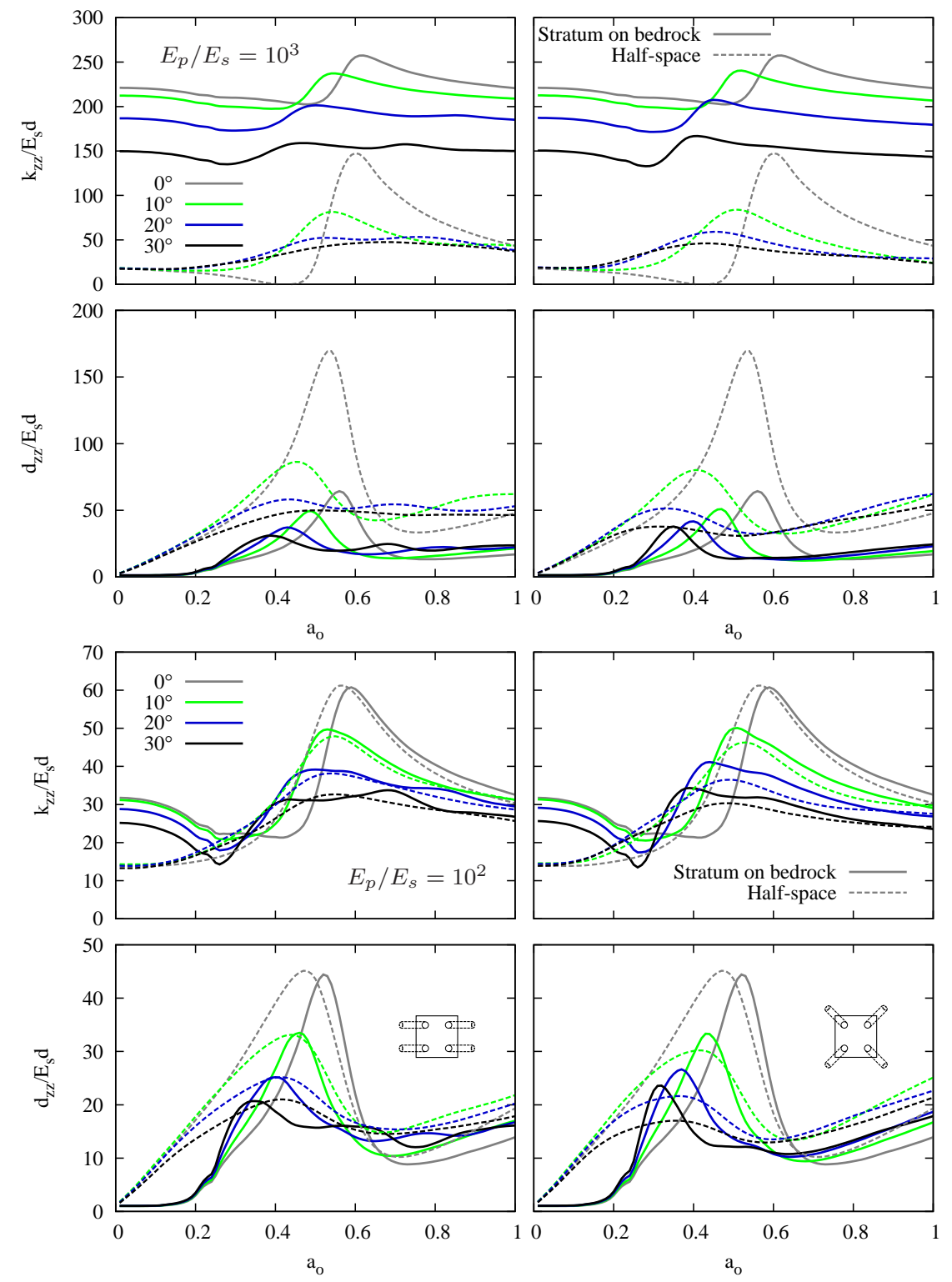

Figure 14: Vertical impedance functions for $2 \times 2$ pile groups with inclined elements. $s / d=5$. $E_{p} / E_{s}=10^{3}$ (top) and $E_{p} / E_{s}=10^{2}$ (bottom). 

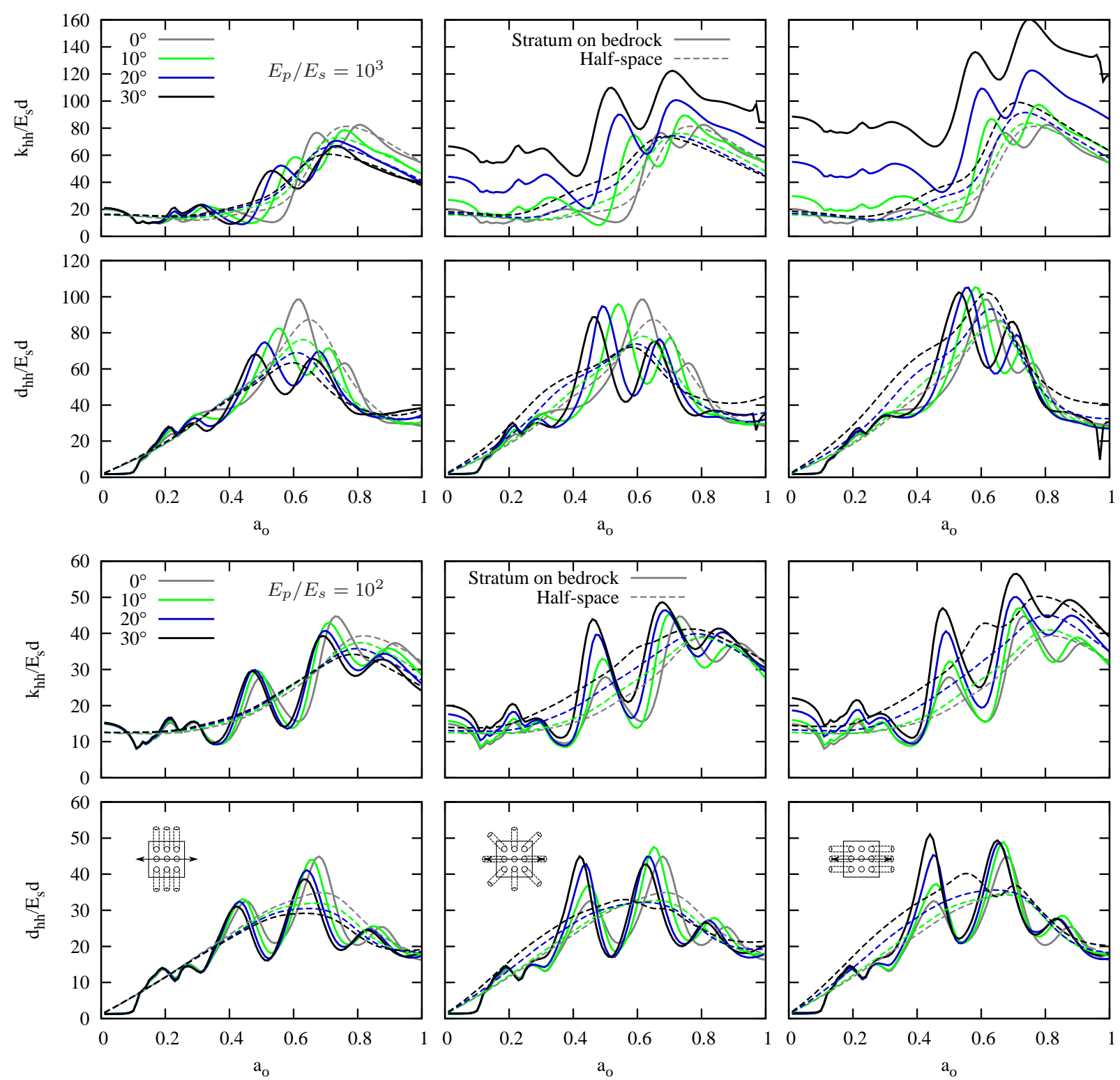

Figure 15: Horizontal impedance functions for $3 \times 3$ pile groups with inclined elements. $s / d=5$. $E_{p} / E_{s}=10^{3}$ (top) and $E_{p} / E_{s}=10^{2}$ (bottom). 

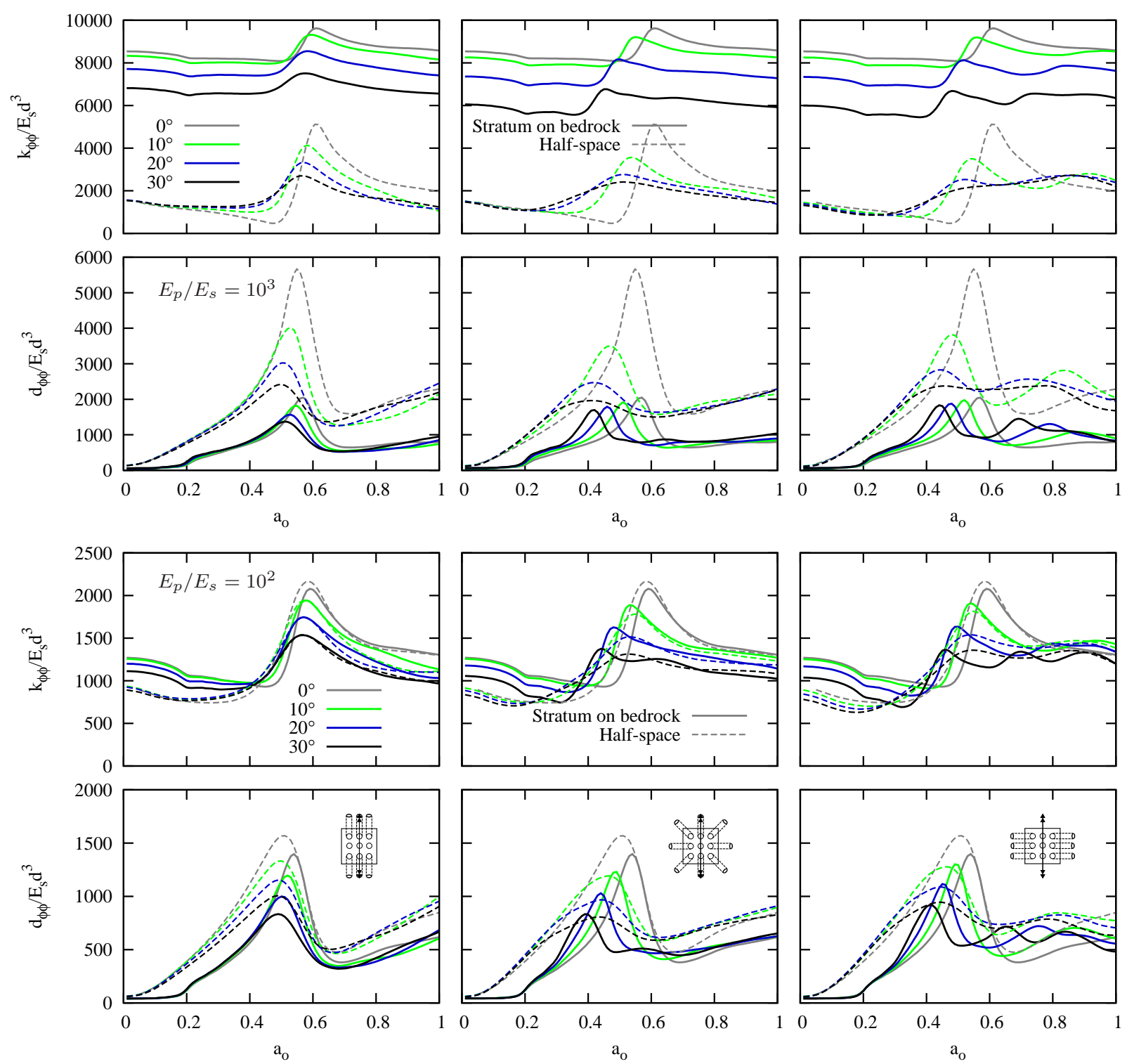

Figure 16: Rocking impedance functions for $3 \times 3$ pile groups with inclined elements. $s / d=5$. $E_{p} / E_{s}=10^{3}$ (top) and $E_{p} / E_{s}=10^{2}$ (bottom). 

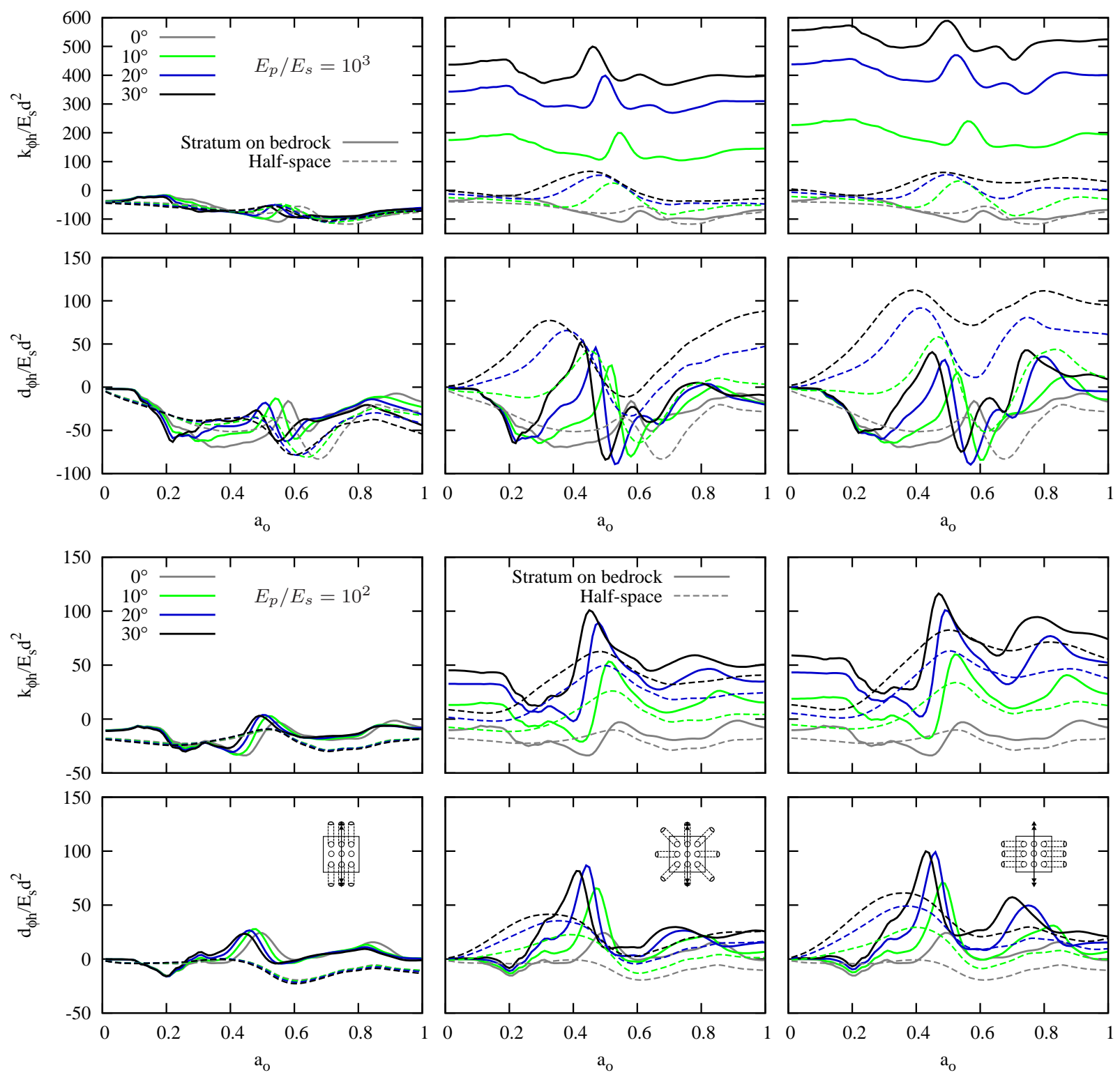

Figure 17: Crossed horizontal-rocking impedance functions for $3 \times 3$ pile groups with inclined elements. $s / d=5$. $E_{p} / E_{s}=10^{3}$ (top) and $E_{p} / E_{s}=10^{2}$ (bottom). 

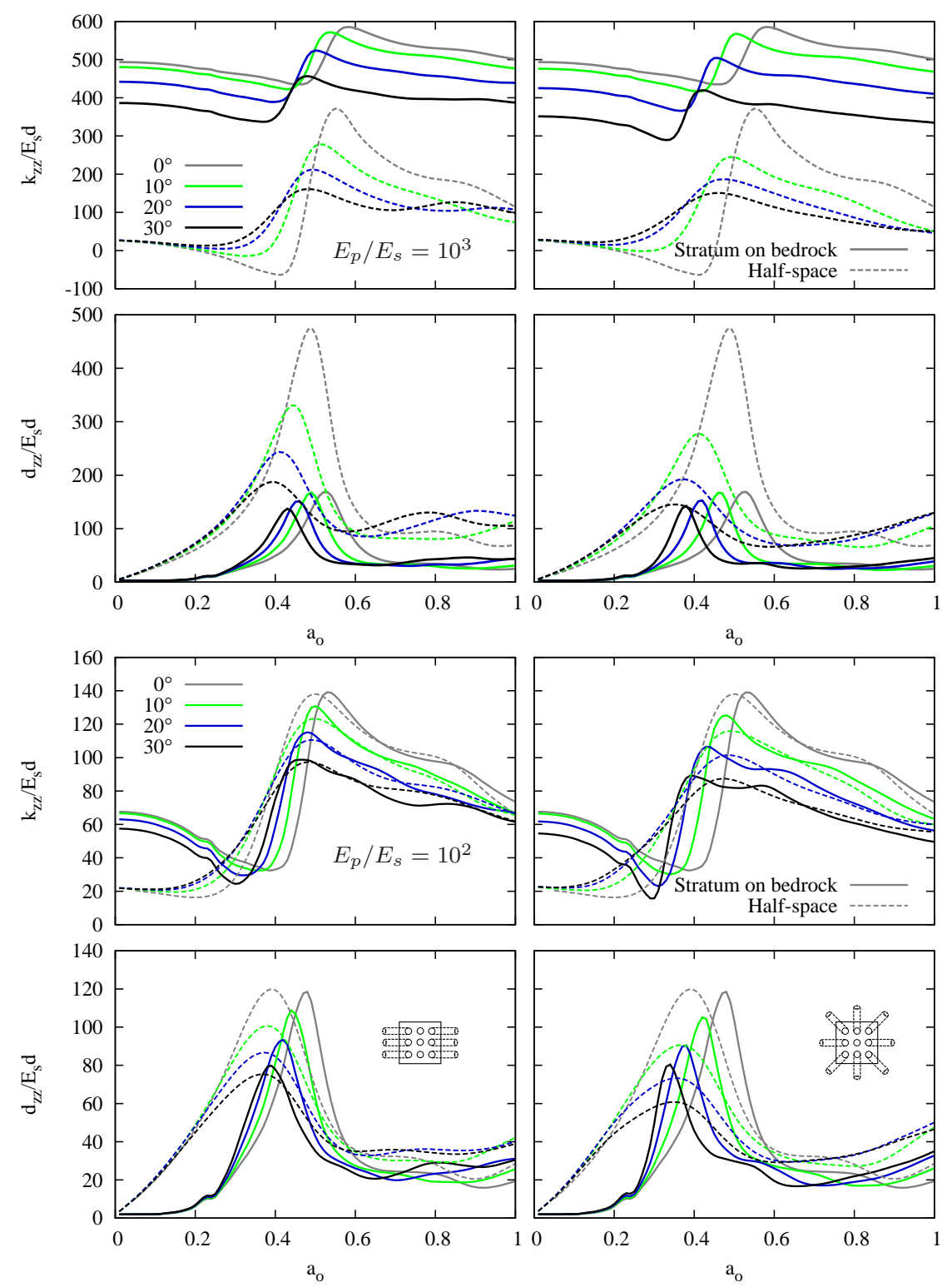

Figure 18: Vertical impedance functions for $3 \times 3$ pile groups with inclined elements. $s / d=5$. $E_{p} / E_{s}=10^{3}$ (top) and $E_{p} / E_{s}=10^{2}$ (bottom). 

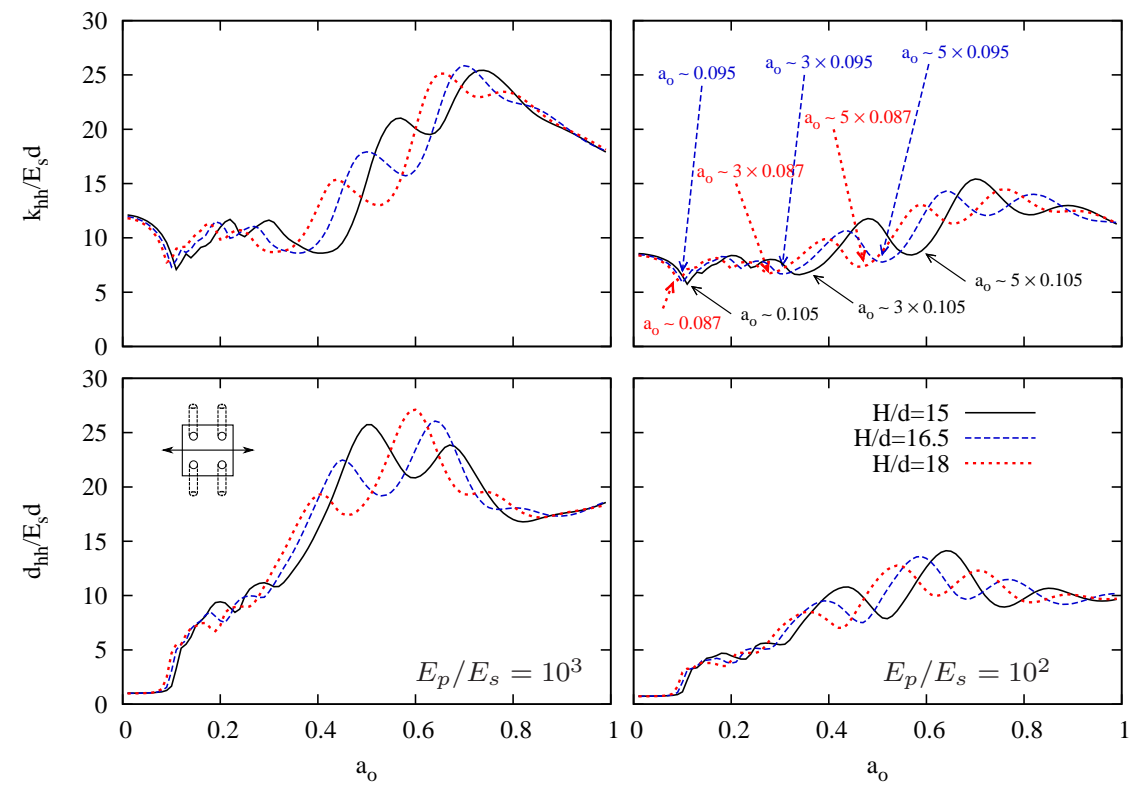

Figure 19: Horizontal impedance functions for $2 \times 2$ pile groups with inclined elements. Comparison for different soil layer depths. $s / d=5, L / d=15, \theta=10^{\circ}, E_{p} / E_{s}=10^{3}$ (left) and $E_{p} / E_{s}=10^{2}$ (right).
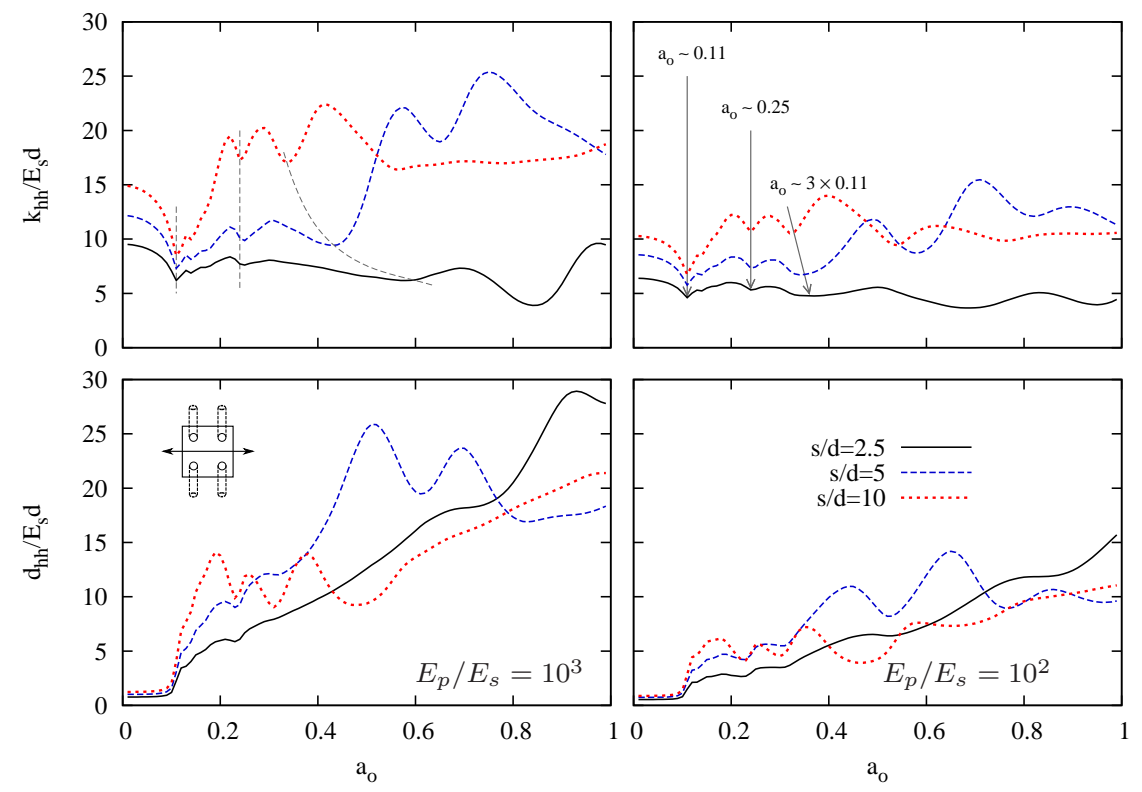

Figure 20: Horizontal impedance functions for $2 \times 2$ pile groups with inclined elements. Comparison for different pile-to-pile separation ratios. $H / d=15, \theta=10^{\circ}, E_{p} / E_{s}=10^{3}$ (left) and $E_{p} / E_{s}=10^{2}$ (right). 